\title{
TAM Derived Construct of Perceived Customer Value and Online Purchase Behavior: An Empirical Exploration
}

\author{
Kok-Wai Chew, P.M Shingi, Mohd. Ismail Ahmad \\ Faculty of Management, Multimedia University, Jalan Multimedia, \\ 63100 Cyberjaya, Selangor, Malaysia \\ kwchew@mmu.edu.my, shingi@mmu.edu.my mohd.ismail@mmu.edu.my
}

\begin{abstract}
Technology Acceptance Model (TAM) was initially created to be a simple model to explain specific technology behavior in information systems. Over the last 18 years, due to its popularity, the TAM has been augmented by including various context-specific constructs to explain phenomenon in e-commerce, e-learning, ebanking, and wireless technologies besides information systems. This study, in the context of e-commerce, or more specifically the online purchase behavior, attempts to consolidate a cohort of existing constructs using the emerging tenets of Customer Valuebased Theory and reinstate the parsimonious intentions of TAM. A total of 1730 questionnaires were collected from Internet users who owned a credit card. The respondents came from all the State capitals in Malaysia, including Cyberjaya, which is the smart city of the Multimedia Super Corridor in Malaysia. Out of 1730 questionnaires, 1440 formed the sample for further data analysis. Bivariate, partial correlations and stepwise multiple regression were used in this study to determine the impact of customer value. The results have shown that Perceived Customer Value is an important determinant of Online Transactions Behavior. With the presence of Perceived Customer Value, only Behavioral Intention is a significant predictor on Online Purchase Behavior. Hence, the Customer Value-Based Model is proposed to obtain a parsimonious conceptualization in predicting consumer acceptance of e-commerce transactions.
\end{abstract}




\section{Introduction}

Technology Acceptance Model (TAM) [1] was initially created to be a simple model to explain specific technology behavior in information systems. Over the last 18 years, due to its popularity, the TAM has been augmented by including various context-specific constructs to explain phenomenon in e-commerce, e-learning, ebanking and wireless technologies besides information systems. As context changed, the researchers added appropriate additional constructs to the basic conceptual stock to bring in the relevant factors in the model. Instead of the original five main constructs, today one is tempted to use as many as 18 constructs, and their interrelated complexities, depending on the nature and the scope of the study [2]. Furthermore, while most of these constructs were conceptually sound, they displayed weak theoretical support in their zest to build models instead of explaining the targeted behavior. This study, in the context of e-commerce, or more specifically the online purchase behavior, attempts to consolidate a cohort of existing constructs using the emerging tenets of Customer Value-based Theory [3] and reinstate the parsimonious intentions of TAM.

\section{Technology Acceptance Model}

Technology Acceptance Model (TAM)) expounded for modeling user acceptance of information systems is an adaptive modification of Theory of Reasoned Action (TRA) [1]. The aim of TAM was to explain user behavior across a broad range of computing technology in a parsimonious way and based on a theoretical foundation. TAM identified a small number of fundamental variables dealing with cognitive and affective determinants, along with two specific beliefs, perceived usefulness (PU) and perceived ease of use (PEOU), posited as constructs of primary importance for computer acceptance behaviors (see Figure 1).

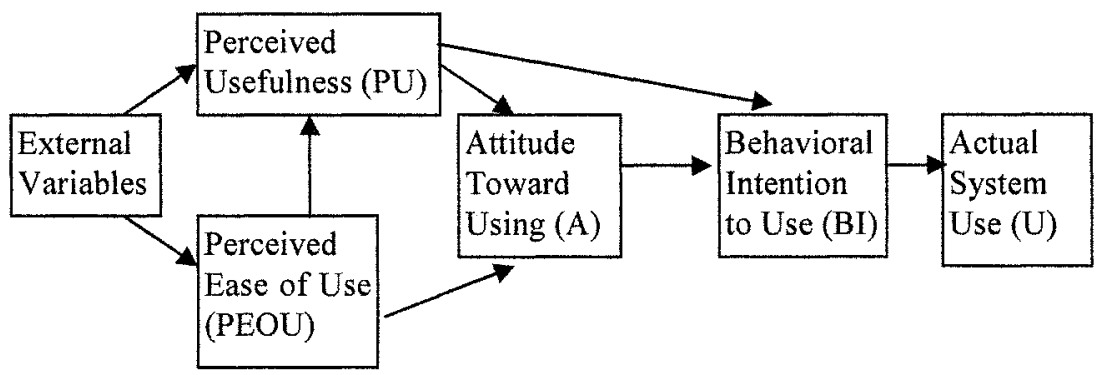

Fig. 1: Technology Acceptance Model

There is a significant relationship among TAM constructs namely Attitude and Behavioral Intentions, on the one hand, and the Usage Behavior on the other $[4,5]$. In more recent modifications, perceived risks of different kinds, Perceived Trust of 
different kinds, and Facilitating Conditions have found place in explaining intermediate, or more specifically TAM specific basic constructs.

In the context of e-commerce, the authors could identify a sufficiently large number of constructs which over a span of 8-10 years found entry into TAM specific literature. Besides PU and PEOU, some of these constructs included: Perceived Convenience, Perceived Enjoyment, Trust in Online Companies, Trust in Internet Security Technology, Perceived Financial Risk, Perceived Physical Risk, Perceived Performance Risk, Perceived Psychological Risk, Perceived Social Risk, Perceived Time Loss Risk, Perceived Privacy Risk, Perceived Overall Risk, and Facilitating Conditions.

These additions probably reflected the complex nature of technology acceptance behavior. Furthermore, as behavioral context kept changing, like that from acceptance of e-mail and graphic systems in the late eighties to that of online purchase, online banking, and e-learning in early twenty-first century, the context specific constructs found several applications. The question remained whether the theoretical base which supported the original TAM conceptualizations remained valid for the emerging context of online transaction based consumer-behaviour. We would like to argue that a broad based and appropriate theoretical framework is needed to explain and account for an emerging battery of constructs more meaningfully. Against this backdrop we would to propose and empirically explore the utility of customer-value based theoretical conceptualizations.

\section{Customer Value}

Slater [3] reports that foundation for the customer value-based theory of the firm was laid decades ago by Alderson [6] and Drucker [7], among others, and was further developed by many marketing theorists. Unprecedented socioeconomic and demographic changes, growing demand for higher levels of quality and service, emergence of new media and distribution channels, rapid rate of technological changes, and hypercompetitive environments are forcing firms to organize themselves around customer value delivery processes. Customer value-based businesses strive to develop better understanding of the customers and focus on intangible value proposition.

\section{Research Questions and Propositions}

Can customer value-based conceptualizations be used to supplement the Technology Acceptance model in predicting online purchase behavior? Can the cohort of existing TAM tested constructs be appropriate utilized to develop an independent scale for measuring customer value? In what way the well established relationships between cognitive, affective, and facilitating variables are likely to get altered as a 
result of alternative conceptualization? In other words, the objective of the paper is to explore the usefulness of incorporating the customer value-based concept in TAM model.

Based on the findings of the previous TAM specific studies as well as the intended research questions, we are proposing the following seven hypotheses for testing.

H1: Customer attitude towards online purchase behavior has significant and positive relationship with online purchase behavior.

H2: Customer's behavioral intention towards online purchase behavior has significant and positive relationship with online purchase behavior.

H3: Trust in Online Companies in the context of e-commerce transactions has significant and positive relationship with online purchase behavior.

H4: Trust in Internet Security Technology in the context of e-commerce transactions has significant and positive relationship with online purchase behavior.

H5: Facilitating Conditions in the context of e-commerce transactions has significant and positive relationship with online purchase behavior.

H6: Perceived Customer Value in the context of e-commerce transactions has significant and positive relationship with online purchase behavior.

Derived from these six hypotheses, in the context of Perceived Customer Value, a null hypothesis is proposed as follows:

H7: The relationship between Attitude, Behavioral Intention, Trust in Online Companies, Trust in Internet Security Technology, and Facilitating Conditions, on the one hand, and actual Online Purchase Behavior would remain positive and significant even when the influence of Perceived Customer Value is controlled for.

\section{Computation of Composite Index of Perceived Customer Value}

Researchers and managers tend to agree that delivering superior customer value is essential to favorably gain consumer response and retain competitive advantage in turbulent market place. Conceptualization and measurement of perceived customer value as a construct, however, remained challenging [see $3,8,9,10]$. In their efforts to discover appropriate scales or empirical referents, the researchers made various observations. Some of these included (a) customer value is customer centric and customer driven; (b) it is judgmental; (c) it is evaluative; (d) besides attributes driven, it is consequences driven, actual or perceived; (e) it is an overall assessment of utility, perceived worth, and/or trade off between price and perceived benefits; (f) it is dynamic in the sense it differs over time for same customers or differs across different customers at the same time; $(\mathrm{g})$ it may intrinsic as well as extrinsic; $(\mathrm{h})$ it 
involved high level of abstraction; (i) It is contextual; (j) it is highly personal; $(\mathrm{k})$ it is multidimensional; (l) it has decision-making implications; and (m) it refers to monetary as well as non-monetary consequences $[3,8,9,10,11]$. All these observations point out that operationalizing the construct of customer value is quite complex. While some admirable efforts have been made to develop independent scales for different objectives, in the context of e-commerce and technology acceptance conceptualizations, we have adopted the following operational definition of the perceived customer value. This operational definition comes closer to Zeithaml's [8 p.14] overall conceptualization that "perceived value is consumer's overall assessment of the utility...based on perceptions of what is received and what is given". Zeithaml does make a reference to benefits and sacrifice components of perceived customer value. Based on these observations and the available stock of TAM specific constructs, we have used the following formula to compute the composite index of perceived customer value:

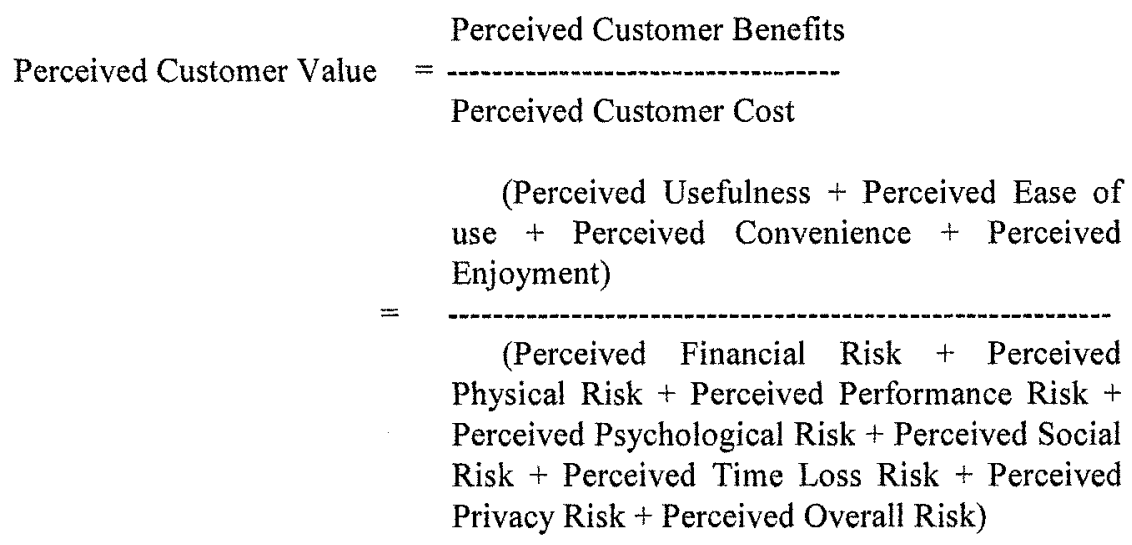

As can be seen from the formula, perceived customer value is a ratio of perceived customer benefits associated with the reference response and the perceived customer costs. In this study the summative index of perceived benefits included four constructs namely Perceived Usefulness, Perceived Ease of use, Perceived Convenience, and Perceived Enjoyment. Similarly, the summative index of perceived cost included eight constructs namely Perceived Financial Risk, Perceived Physical Risk, Perceived Performance Risk, Perceived Psychological Risk, Perceived Social Risk, Perceived Time Loss Risk, Perceived Privacy Risk, and Perceived Overall Risk associated with the reference transaction.

In our study we have considered PEOU as a benefit to the customer for a variety of reasons. Though PEOU has been found to be an antecedent of PU in TAM specific literature, in the original model it also had direct causal influence on the attitude. In a given context, affirmative perceptions regarding ease of use can have positive decision making consequences. In the similar vein, negative perceptions can be treated as a cost parameter. Positive perceptions on the other hand reflect an overall favorable assessment of the utility and its potentially beneficial worth. 


\section{Methodology}

The variables and the number of items describing the variables for this study are summarized below. All items were measured using 5-point Likert scale.

\subsection{Actual Online Purchase}

For the purpose of this study, actual online purchase of air tickets is used as the dependent variable. The data collected from the respondents included the number of air tickets purchased through (a) travel agency, (b) the Internet and (c) airline counters, for business, personal and family travel together, within the last 12 months from the date the survey was conducted. For data analysis purpose, the number of tickets bought through Internet as a percentage of the total tickets bought from all sources for all purposes was used as a variable.

Airline ticket purchases were chosen to test our model because the price for airline tickets generally remains same regardless of the channel of purchase, i.e. either through the travel agent, airline ticketing counter, or the Internet. The focus of our customer value-based model for e-commerce is only for online purchase behavior, hence the actual costs associated with other channels like cost of driving to travel agency, parking the car or calling the travel agency vs. making the booking online were not considered in our model.

Perceived Usefulness: The original scale used by Davis [4] to measure Perceived Usefulness of electronic mail was modified to reflect the buying of an airline ticket on Internet. The Cronbach alpha value for the seven items in the final survey was 0.91 .

Perceived Ease of Use: The original scale used by Davis [4] to measure Perceived Ease of Use of electronic mail was adapted to suit the context of purchasing an airline ticket online. The Cronbach alpha value for the four items in the final survey was 0.74

Perceived Convenience: Three items measuring perceived convenience of technology assisted shopping [12] were modified to suit the context of online purchase. The Cronbach alpha value for the three items was 0.85 in the main survey.

Perceived Enjoyment: Three items measuring perceived enjoyment of websites [13] and two items measuring perceived enjoyment of technology assisted shopping [12] were modified to suit the context of online purchase. The Cronbach alpha value for the four items was 0.90 in the main survey.

Financial Risk: Three items measuring financial risk for online shopping [14] and two items measuring financial risk of e-services adoption [15] were modified to suit the context of online purchase. The Cronbach alpha value for all the five items for the main study was 0.80 . 
Physical Risk: Two items measuring physical risk for online shopping [14] were modified to suit the context of online purchase. The Cronbach alpha value for both items was 0.85 in the main study.

Performance Risk: One item measuring performance risk for online shopping [14] and three items measuring performance risk of e-services adoption were modified to capture information about online purchase for this study. The Cronbach alpha value for all the four items was 0.89 in the main study.

Psychological Risk: Three items from Kehoe's study [14] and one item from Featherman and Pavlou's [15] study were modified to suit the context of online purchase. In the main study, the Cronbach alpha value for all the four items was 0.90 .

Social Risk: Three items measuring social risk [14] for online shopping were modified to suit the context of online purchase. The Cronbach alpha value for all the three items was 0.87 in the main study.

Time-Loss Risk: Four items measuring time-loss risk for online shopping [14] were modified to suit the context of online purchase. The Cronbach alpha value for all the four items was 0.91 in the main study.

Privacy Risk: Two items measuring privacy risk of e-services adoption [15] were modified to suit the context of online purchase. The Cronbach alpha value for both items is 0.90 in the main study.

Overall Risk: Four items used to measure overall risk of online shopping [14] and two additional items to measure the overall risk of e-services adoption [15] were modified to reflect online purchase of airline tickets. The Cronbach alpha value for all the six items in the final study was 0.90 .

Trust in Online Company: All the items from two studies $[14,16]$ were modified to suit the context of online purchase of airline tickets. The Cronbach alpha value for all the six items in the final study was 0.89 .

Trust in Internet Security Technology: The initial scale measuring Trust in Internet Security Technology for online shopping was modified to reflect the context of online purchase. The Cronbach alpha value for all the five items in the final survey was 0.94 .

Facilitating Conditions: Items measuring facilitating condition for the intention to use Internet/WWW at work [17] were modified to determine the facilitating condition of the Internet for purchase. In the main survey, the Cronbach alpha value for both items was 0.80 . 


\subsection{Sample and Data Collection}

A pilot study to test the study instrument for the main survey was carried out by interviewing undergraduates enrolled in an electronic business course at a large private university in Malaysia. Undergraduates vary widely in their skills and knowledge, and this variance helped in being able to clarify the wording, content, and general layout of the survey instrument.

The population for the main survey consisted of Internet users who had credit cards and their own income. Online purchase can only be done by someone who was familiar with the Internet and owned a credit card. Similarly, they must be earning to be in a position to buy products online. Therefore, the respondents who fulfilled the following three criteria were selected for obtaining responses: (a) use the Internet; (b) has a credit card; and (c) currently working or self-employed.

Since the sampling was limited to a specific target group, purposive sampling was considered suitable as a sampling design [18]. This method was appropriate to collect data from specific types of people who could provide the desired information. A total of 1730 respondents filled the questionnaires, mostly in the presence of investigators. The sample was drawn from the capital cities of all the states in Malaysia, including Cyberjaya which is the "Smart City" in the Malaysia's Multimedia Super Corridor. State capitals and Cyberjaya were chosen as the locations to collect data as prospects of both the population and the respondents fulfilling the three criteria were better as compared to small towns and rural areas since Malaysia is still a developing country.

A survey method was preferred for this study as responses on a large number of scale specific items were needed to systematically measure various constructs. The scales used in this study were derived from previous studies which had also used the survey method. Survey method also allowed us to get a sizable number of responses and be consistent with previous TAM studies. This consistency was needed for the purpose of this study.

Of the 1730 questionnaires, 120 questionnaires were discarded as many items in the questionnaire were not answered. Furthermore, 170 respondents indicated that they were not aware that airline tickets could be bought through the Internet. Since online purchase required the Internet users to be aware of this possibility, responses of these 170 respondents were not used for data analysis. Thus 1440 respondents who were aware that airline tickets could be bought through the Internet formed the sample of this study.

The authors had access to data which could be analyzed using sophisticated techniques such as structural equation models. Since the primary purpose was exploration, analysis based on simple bivariate, partial correlations and stepwise multiple regression was preferred to more effectively determine the impact of customer value. Version 12 of SPSS was used to process the data. 


\section{Results}

\subsection{Demographics}

Around half of the sample were male $(51.4 \%, n=740)$. The major ethnic groups in Malaysia were well represented in the sample [41\% Malays $(n=591), 36.0 \%$ Chinese $(n=519), 20.8 \%$ Indian $(n=299)$ and $2.2 \%$ other ethnic groups $(n=31)]$. The youngest respondent is 18 years old while the oldest respondent is 64 . The mean was 33 years with the standard deviation of $8.152 .20 .3 \%$ have primary or secondary school qualifications $(\mathrm{n}=289)$, while $69.9 \%(\mathrm{n}=1006)$ has either certificates, diploma, bachelor's degree or professional qualifications and $7.3 \%$ have Masters and $\mathrm{PhD}$ degrees $(n=105) .1 .3 \%$ did not mention their highest academic qualification $(n=19)$.

\subsection{Hypotheses Testing}

Table 1: Influence of Perceived Customer Value on other variables.

\begin{tabular}{|l|l|r|}
\hline \multirow{2}{*}{$\begin{array}{l}\text { Control } \\
\text { Variables }\end{array}$} & \multicolumn{2}{|c|}{$\begin{array}{l}\text { Tickets bought from } \\
\text { Internet as \% of tickets } \\
\text { bought from all sources }\end{array}$} \\
\hline None-(a) & $\begin{array}{l}\text { Tickets bought from Internet as \% of } \\
\text { tickets bought from all sources }\end{array}$ & 1.00 \\
\hline & Attitude toward Online Purchase & $.175\left(^{* *}\right)$ \\
\hline & Behavioral Intention & $.239\left(^{* *}\right)$ \\
\hline & Trust in Online Companies & $.173\left(^{* *}\right)$ \\
\hline & Trust in Internet Security Technology & $.141\left(^{* *}\right)$ \\
\hline & Facilitating Conditions & $.157\left(^{* *}\right)$ \\
\hline $\begin{array}{l}\text { Perceived } \\
\text { Customer } \\
\text { Value }\end{array}$ & $\begin{array}{l}\text { Rickets bought from Internet as \% of } \\
\text { tickets bought from all sources }\end{array}$ & $.293\left(^{* *}\right)$ \\
\hline & Attitude toward Online Purchase & 1.000 \\
\hline & Behavioral Intention & .022 \\
\hline & Trust in Online Companies & $.090\left(^{*}\right)$ \\
\hline & Trust in Internet Security Technology & .043 \\
\hline & Facilitating Conditions & .017 \\
\hline
\end{tabular}

** Correlation is significant at 0.01 level, * Correlation is significant at 0.05 level, a Cells contain zero-order (Pearson) correlations. 
The results of the hypotheses testing are shown in Table 1. The results indicated that all the six hypotheses were supported. This meant that the relationships between variables like Attitude $(r=0.18)$, Behavioral Intention $(r=0.24)$, Trust in Online Companies $(r=0.17)$, Trust in Internet Security Technology $(r=0.14)$, Facilitating Conditions $(r=0.16)$ and Perceived Customer Value $(r=0.29)$, on the one hand, and actual Online Purchase Behavior on the other were significant at 0.01 level. These results were in the expected direction. However, when Perceived Customer Value was used as a control variable, the results of the partial correlations showed that all relationships between Attitude $(r=0.02)$, Behavioral Intention $(r=0.094)$, Trust in Online Companies $(r=0.04)$, Trust in Internet Security Technology $(r=0.02)$, Facilitating Conditions $(r=0.01)$ and actual Online Purchase Behavior became nonsignificant except Behavioral Intention which showed substantial reduction in its impact on actual air ticket purchase online and which was marginally significant at 0.05 level. Therefore, $\mathrm{H} 7$ as a null hypothesis was rejected.

Consistent with the above results, the results of the stepwise multiple regression, as shown in Table 2, indicated that perceived customer value was the most significant $(\mathrm{p}<0.01)$ predictor of online transaction behavior followed by behavioral intention $(\mathrm{p}<0.05)$. All the other variables got excluded from the analysis.

Table 2: Stepwise multiple regression results for Perceived Customer Value

\begin{tabular}{|l|l|r|r|r|r|r|}
\hline \multirow{2}{*}{ Model } & & \multicolumn{2}{|c|}{$\begin{array}{c}\text { Unstandardized } \\
\text { Coefficients }\end{array}$} & $\begin{array}{l}\text { Standardized } \\
\text { Coefficients }\end{array}$ & \multicolumn{1}{c|}{$\mathrm{t}$} & Sig. \\
\cline { 2 - 7 } & \multicolumn{1}{c|}{$\mathrm{B}$} & $\begin{array}{c}\text { Std. } \\
\text { Error }\end{array}$ & \multicolumn{1}{c|}{ Beta } & & \\
\hline 1 & (Constant) & 3.633 & 3.938 & & .923 & .357 \\
\hline 2 & $\begin{array}{l}\text { Ratio of Perceived } \\
\text { Customer Value }\end{array}$ & .334 & .040 & .292 & 8.285 & .000 \\
\hline & $\begin{array}{l}\text { (Constant) } \\
\text { Ratio of Perceived } \\
\text { Customer Value }\end{array}$ & .268 & .049 & .234 & 5.432 & .000 \\
\hline & \begin{tabular}{l} 
Behavioral Intention \\
\hline
\end{tabular} & 1.883 & .814 & .100 & 2.313 & .021 \\
\hline
\end{tabular}

Dependent Variable: Tickets bought from Internet as \% of tickets bought from all sources

\section{Discussions}

The results have shown that Perceived Customer Value is an important determinant of Online Purchase Behavior. So far, this key construct has not been used with TAM for e-commerce in previous studies. With the presence of Perceived Customer Value, only Behavioral Intention is a significant predictor on Online Purchase Behavior. Hence, the Customer Value-Based Model (Figure 2) is proposed to obtain a 
parsimonious conceptualization in predicting consumer acceptance of e-commerce transactions. Since constructs such as trust and facilitating conditions were found not significant due to the influence of Perceived Customer Value, these constructs were not included in the proposed Customer Value-Based Model.

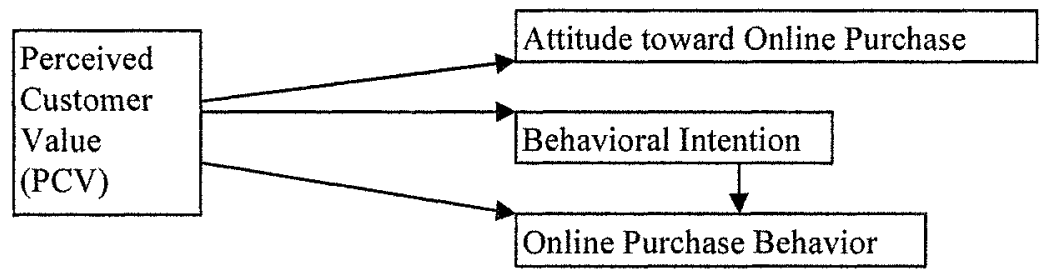

Fig. 2: Customer Value-Based Model for e-Commerce

\section{Conclusions}

Perceived Customer Value as a sound theoretical construct has important implications for online purchase behavior. Though this construct is increasingly gaining ground in the field of marketing, it has equal relevance for the field of ecommerce.

\section{Acknowledgement}

The authors are grateful for the financial support received from IRPA, Ministry of Science, Technology and Innovation, Malaysia for the conduct of original study and Multimedia University, Malaysia for allowing us to use the data.

\section{References}

1. F. D. Davis, R. P. Bagozzi and P. R. Warshaw, User acceptance of computer technology: A comparison of two theoretical models. Management Science 35(8), 982-1003 (1989).

2. P. Legris, J. Ingham and P. Collerette, Why do people use information technology? A critical review of the technology acceptance model Information \& Management 40(3), 191-204 (2003).

3. S. F. Slater, Developing a customer value-based theory of the firm Journal of the Academy of Marketing Science 25(2), 162-167 (1997). 
4. F. D. Davis, A technology acceptance model for empirically testing new end-user information systems: Theory and results PhD Dissertation, Massachusetts Institute of Technology, (1986).

5. O. Koppius, W. Speelman, O. Stulp, B. Verhoef and E. v. Heck, "Why are customers coming back to buy their airline tickets online? theoretical explanations and empirical evidence Proceedings of the 7 th international conference on Electronic commerce, Xi'an, China, 319-326 (2005).

6 W., Alderson, Marketing Behavior and Executive Action, Homewood, I L: Irwin (1957).

7. P. F. Drucker, Management, New York: Harper \& Row, (1973).

8. V. A. Zeithaml, Consumer perceptions of price, quality and value: A means-end model and synthesis of evidence Journal of Marketing 52(July), 2-22. (1988).

9. R. B. Woodruff, Customer value: the next source of competitive advantage Journal of the Academy of Marketing Science 25(2), 139-153 (1997).

10. A. Parasuraman, Reflections on gaining competitive advantage through customer value Journal of the Academy of Marketing Science 25(2), 154-161 (1997).

11. J. F. Petrick, Development of a multi-dimensional scale for measuring the perceived value of a service Journal of Leisure Research 34(2), 119-134 (2002).

12. T. L. Childers, C. L. Carr, J. Peck and S. Carson, Hedonic and utilitarian motivations for online retail shopping behavior Journal of Retailing 77(4), 511-535 (2001).

13. H. Heijden, Factors influencing the usage of websites: the case of a generic portal in The Netherlands. Information \& Management 40(6), $541-549$ (2003).

14. M. Kehoe, The Role of Perceived Risk and Consumer Trust in Relation to Online Shopping and Security (PhD Dissertation. The Florida State University), (2002).

15. M. S. Featherman and P. A. Pavlou, Predicting E-Services Adoption: A Perceived Risk Facets Perspective. International Journal of Human-Computer Studies 59(4), USA,451-474 (2003).

16. G. Hackbarth, V. Grover, and M. Y. Yi, Computer playfulness and anxiety: positive and negative mediators of the system experience effect on perceived ease of use. Information and Managemen, t 40(3), pp 221-232 (2003)

17. M. K. Chang and W. Cheung, Determinants of the intention to use Internet/WWW at work: a confirmatory study. Information \& Management 39(1), 114, The Netherlands (2001). 
TAM Derived Construct of Perceived Customer Value and Online Purchase

Behavior: An Empirical Exploration

18. U. Sekaran, Research Methods for Business, 4th Edition John Wiley \& Sons, Inc., (2003). 